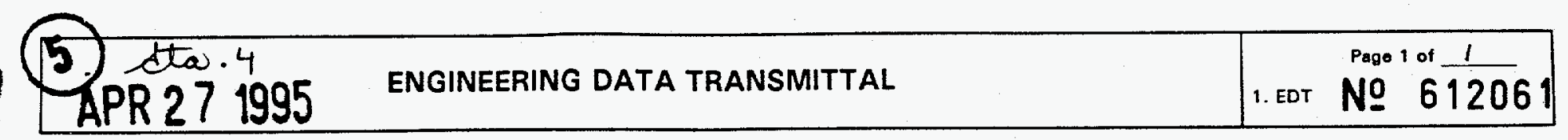

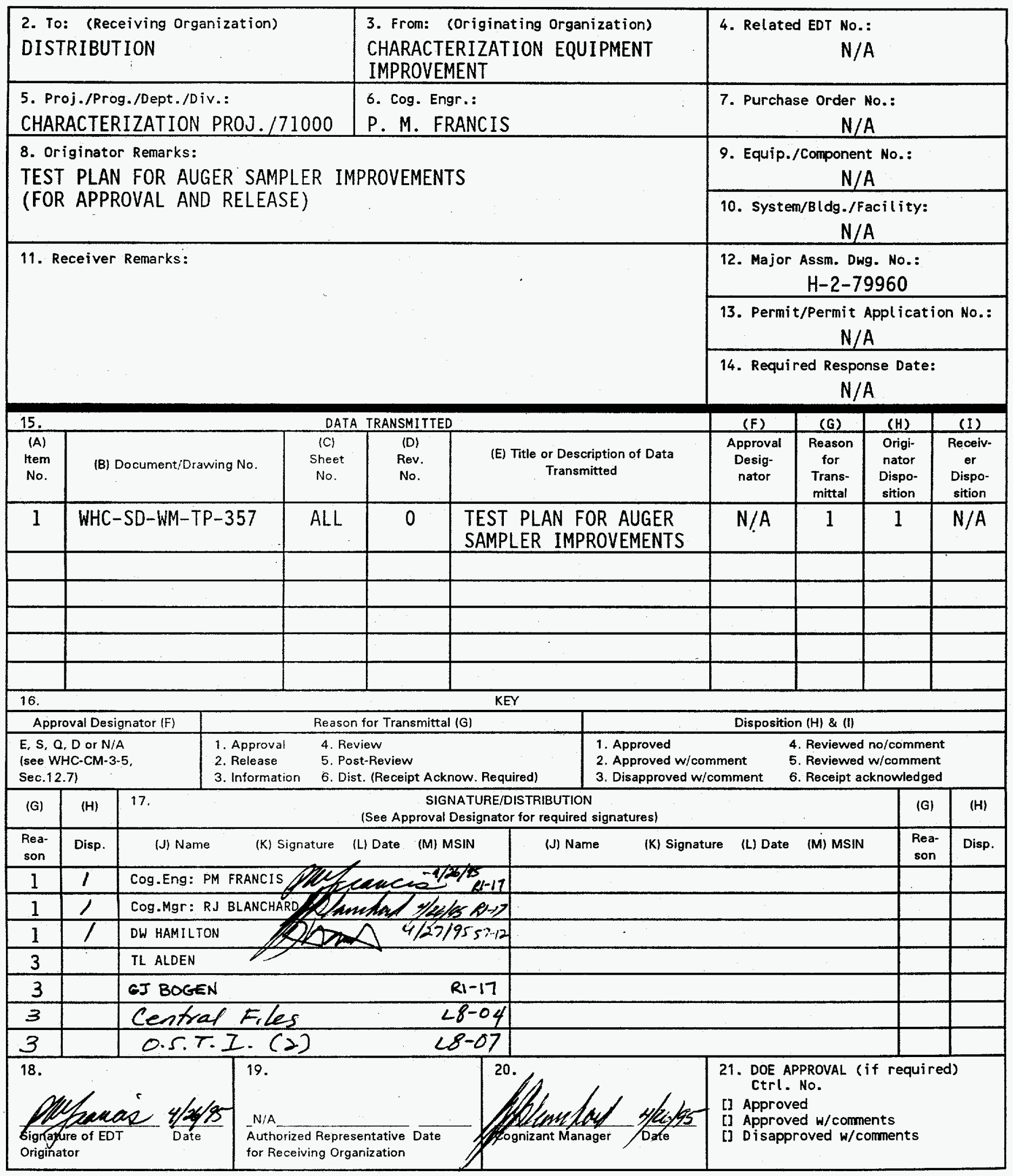




\section{DISCLAIMER}

Portions of this document may be illegible in electronic image products. Images are produced from the best available original document. 


\section{RELEASE AUTHORIZATION}

Document Number: WHC-SD-WM-TP-357, REV 0

Document Title: $\quad$ Test Plan for Auger Sampler Improvements

Release Date: $\quad 4 / 27 / 95$

\section{This document was reviewed following the} procedures described in WHC-CM-3-4 and is:

\section{APPROVED FOR PUBLIC RELEASE}

WHC Information Release Administration Specialist:

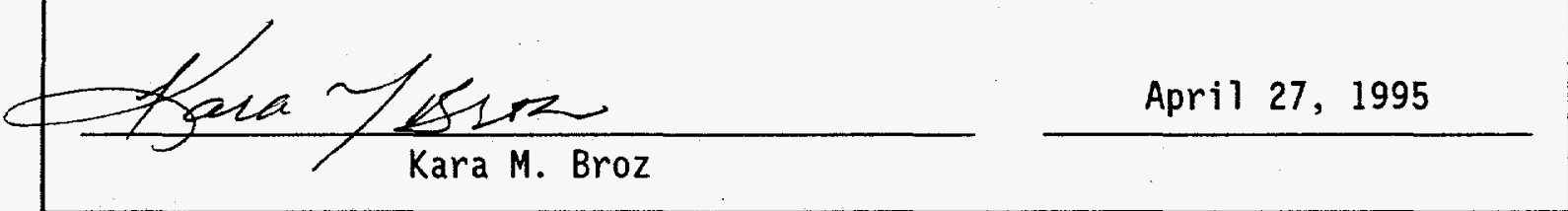

TRADEMARK DISCLAIMER. Reference herein to any specific comercial product, process, or service by trade name, trademark, manufacturer, or otherwise, does not necessarily constitute or imply its endorsement, recommendation, or favoring by the United states Govermment or any agency thereof or its contractors or subcontractors.

This report has been reproduced from the best available copy. Available in paper copy and microfiche. Printed in the United states of America. Available to the U.S. Department of Energy and its contractors from:

U.S. Department of Energy

Office of Scientific and Technical Information (OSTI)

P.0. Box 62

Oak Ridge, TN 37831

Telephone: (615) 576-8401

Available to the public from:

U.S. Department of Commerce

National Technical Information Service (NTIS)

5285 Port Royal Road

Springfield, VA 22161

Telephone: (703) 487-4650

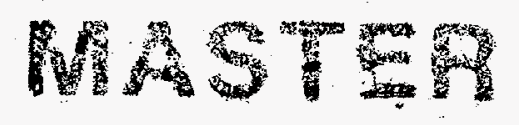




\begin{tabular}{|l|l|c|}
\hline $\begin{array}{l}\text { 2. Title } \\
\text { Test Plan for Auger Sampler Improvements }\end{array}$ & $\begin{array}{l}\text { 3. Number } \\
\text { WHC-SD-WM-TP-357 }\end{array}$ & $\begin{array}{l}\text { 4. Rev No. } \\
0\end{array}$ \\
\hline $\begin{array}{l}\text { 5. Key Words } \\
\text { auger sampler, testing, sample }\end{array}$ & $\begin{array}{l}\text { 6. Author } \\
\text { Name: P. M. Francis }\end{array}$ \\
& $\begin{array}{l}\text { Sighature } \\
\text { Organization/Charge Code 71510/N4053 }\end{array}$ \\
\hline
\end{tabular}

\section{Abstract}

Multiple variations to the auger design will be tested to determine their ability to increase sample recovery and broaden the sampling activities. The designs will be tested in two different media, with recoveries compared to that of a standard auger sampler. Each design modification will be developed and tested using the method described in this test plan.

\section{DISCLAIMER}

This report was prepared as an account of work sponsored by an agency of the United States Government. Neither the United States Government nor any agency thereof, nor any of their employees, makes any warranty, express or implied, or assumes any legal liability or responsibility for the accuracy, completeness, or usefulness of any information, apparatus, product, or process disciosed, or represents that its use would not infringe privately owned rights. Reference herein to any specific commercial product, process, or service by trade name, trademark, manufacturer, or otherwise does not necessarily constitute or imply its endorsement, recommendation, or favoring by the United States Government or any agency thereof. The views and opinions of authors expressed herein do not necessarily state or reflect those of the United States Government or any agency thereof.
8. RELEASE STAMP

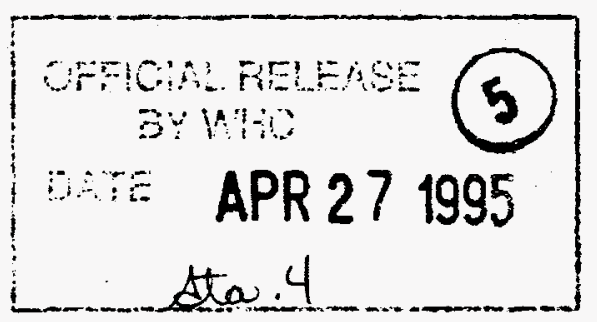


WHC-SD-WM-TP-357 REV. 0

\title{
TEST PLAN FOR AUGER SAMPLER IMPROVEMENTS
}

\author{
PREPARED BY \\ PETER M. FRANCIS \\ Characterization Equipment Improvement \\ Tank Waste Remediation System
}

Westinghouse Hanford Company, Richland, Washington Apri1 1995 
WHC-SD-WM-TP-357 REV. 0

Table of Contents

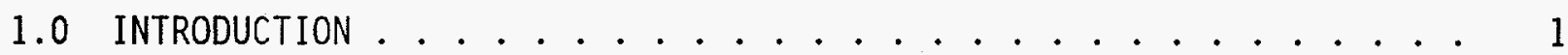

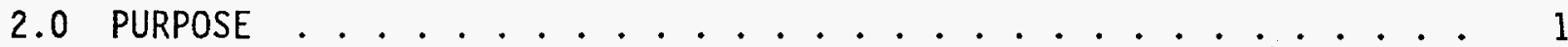

2.1 Background .................... 1

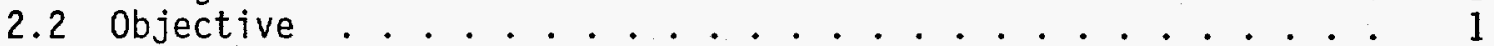

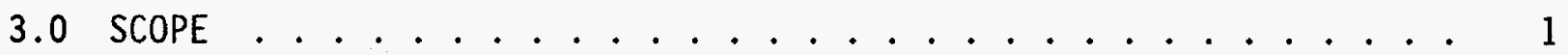

4.0 DESCRIPTION OF TEST ................... 2

4.1 Test Items . . . . . . . . . . . . . . . 2

4.1 .1 Groove Design ............... 2

4.1 .2 Finned Design ................. . . 2

4.1.3 Small Shaft Design . . . . . . . . . . . . . 2

4.1.4 Sheath Design ... . . . . . . . . . . . 2

4.1 .5 Raised Edge Design . . . . . . . . . . . . . . 3

4.1 .6 Rough Finish Design ............... . 3

4.1.7 Shallow Pitch Design .............. . 3

4.2 Test Environment . . . . . . . . . . . . . . 3

4.3 Test Equipment . . . . . . . . . . . . . . 4

4.4 Data . . . . . . . . . . . . . . . . 4

4.5 Criteria and Constraints............... . 4

5.0 EXPECTED RESULTS . . . . . . . . . . . . . . 5

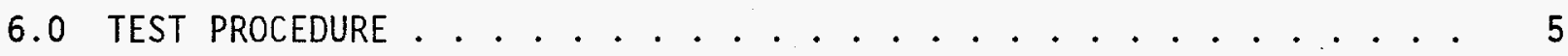

7.0 SAFETY . . . . . . . . . . . . . . 5

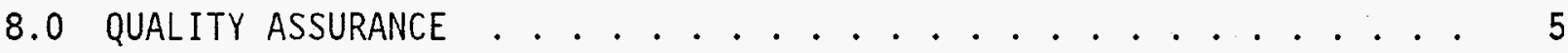

9.0 ORGANIZATION AND FUNCTIONAL RESPONSIBILITIES . . . . . . . . . 6

10.0 SCHEDULE $\ldots \ldots \ldots 6 . \ldots \ldots$

\section{ATTACHMENTS:}

1. Grooved Auger . . . . . . . . . . . . . . . 7

2. Finned Auger .................. 8

3. Small Shaft Auger . . . . . . . . . . . . . . . . 9

4. Sheathed Auger ... . . . . . . . . . . . . 10

5. Raised Edge Auger. . . . . . . . . . . . . . . . . 11

6. Shallow Pitch Auger. . . . . . . . . . . . . . . . 12

7. Tapered Flight Auger . . . . . . . . . . . . . . 13

8. Data Sheet ...................... . . 14

9. Schedule ............................ 15 
WHC-SD-WM-TP-357 REV. 0

\subsection{INTRODUCTION}

The recovery performance of the auger sampler (WHC drawings $\mathrm{H}-2-79960$ and $\mathrm{H}-2-79961)$ has proven inadequate in certain materials. The current auger configuration relies on cohesion and adhesion (properties dependent on sample media) to retain the sample. The media must maintain its form and stick to the auger flights to recover the sample. Recovery has been satisfactory when sampling in wastes with adequate adhesion and shear strength to overcome the forces of gravity and vibrations associated with retrieval.

Multiple variations to the auger design will be tested to determine their ability to increase sample recovery and broaden the sampling capabilities. The designs witl be tested in two different media, with the recoveries compared to that of a standard auger sampler. Each design modification will be developed and tested using the method described in this test plan.

\subsection{PURPOSE}

\subsection{Background}

At Westinghouse Hanford Company (WHC), one of the functions of the Tank Waste Remediation System (TWRS) division is sampling waste tanks to characterize their contents. The auger sampling method, which was originally designed to sample crust layers, captures a short segment from the top of the tank waste. An auger, encased in a cylinder (the "auger tube"), is lowered into a tank on a long shaft. . A handle on the shaft is manually turned at the surface and the sampler is drilled to a depth of as much as 20 inches. At the completion of drilling the auger is pulled into a sheath and withdrawn from the tank by a crane. Auger sampling generally provides satisfactory recovery when used in tanks with hard crusts on the waste surface. Recovery data indicates that sample retention is poor in both nonadhesive (extremely dry) and in low shear strength (liquid) media. Design concepts have been developed with the intent of improving recovery in these waste types.

\subsection{Objective}

The objective of these tests is to find variations to the current auger design that will increase sample recovery and expand the sampler's operability range. This phase of testing will determine the effectiveness of the new design modifications described in 4.1 , Test Items. Further testing should be conducted as a follow up, if the capabilities of auger sampling are to be optimized.

\subsection{SCOPE}

Several tasks are required to accomplish this testing. Design and drafting efforts are required to document the changes intended for the auger bit. The new bits will then be fabricated at WHC shops. The new auger designs will undergo several trials in two different types of simulants. Retesting will be performed as required. A document will then be issued to report the testing results and make recommendations on improving the auger sampler design. This 
WHC-SD-WM-TP-357 REV. 0

effort involves the modification of existing equipment only; no new sampling devices will be included in the testing.

\subsection{DESCRIPTION OF TEST}

\subsection{Test Items}

The auger modifications described below are based upon the current 10-in. auger design (H-2-79961), with deviations from that design only where noted. All of the test augers and the standard will be fabricated from 416 type stainless steel. For convenience, the designs will be termed: groove, fin, small-shaft, sheath, raised edge, rough finished, shallow pitch, tapered flight, and standard. With the exception of the smaller shaft design, all of the modifications have been designed with the intent of better sample retention. The objective of the smaller shaft is to increase the attainable sample recovery volume.

\subsubsection{Groove Design}

It is expected that machining a groove onto the auger flights will prevent sample material from sliding down the auger. This first concept would entail milling a groove radially from the shaft to the outer edge of the flight at an interval of approximately $120^{\circ}$. See Attachment 1, Grooved Auger, for design details.

\subsubsection{Finned Design}

Like the groove design, the fin concept attempts to prevent the sample from spiraling down the flutes. Small vanes, approximately 1/16-in. high and $120^{\circ}$ apart, will be machined into the flights. The vanes will be sloped upward so that material can travel up the flights but is prevented from flowing down. See Attachment 2, Finned Auger, for design details.

\subsubsection{Small Shaft Design}

Capturing more sample with the auger would be desirable for the waste characterization effort. The inner shaft of the auger bit currently has a diameter of 1.00 to 1.03 inches. By reducing the diameter to 0.50 inches, the available sample volume can be increased by more than 33 percent. Smaller shaft designs may be considered, but will be limited in minimum diameter by the machining process. See Attachment 3, Small Shaft Auger, for design details.

\subsubsection{Sheath Design}

A concern has been raised that when the auger bit is drawn up into the auger tube, the sample could be disrupted. It is surmised that the rough walls of the bored hole tend to pull the sample media off of the flutes. There is also a concern that the sample is being smeared or mixed when it is retrieved into the tube. 
To address this perceived problem, the auger tube will be forced down to encase the sample before pulling the auger sampler up. See Attachment 4, Sheathed Auger, for details. For the purposes of testing, a slot will be milled in the side of the drill casing. A screw driver or other tool will be used to force the auger tube down. The auger bit will be of the standard design (H-2-79961). Although a sheathed design that would work for actual operations has not yet been developed, this method will be adequate to test the concept.

\subsubsection{Raised Edge Design}

Like the sheath design, the raised edge is intended to prevent waste from falling off the edge of the flutes. A thin '7ip' will be added on the circumference of the flutes to act as a dam to the waste being recovered. See Attachment 5, Raised Edge Auger, for design details.

\subsubsection{Rough Finish Design}

The surface finish of the augers currently being fabricated are on the order of 16-32 $\mu \mathrm{in}$. (rms). The purpose for this is to allow for easier decontamination. If a rougher surface finish were present, the static coefficient of friction would be higher resulting in better sample retention. For this test, a standard auger will be sandblasted to provide the textured finish. If this modification proves to have merit, future augers could be disposed of and replaced rather than using the current decontamination process.

\subsubsection{Shallow Pitch Design}

Going to a shallower pitch on the auger flights will reduce the resolved gravitational forces acting to pull the sample off the auger. Theoretically, reducing the pitch by half will allow the auger to retain sample media that provide half the static coefficient of friction with the auger flights. However, the added number of flights will reduce the total volume of material collected. See Attachment 6, Shallow Pitch Auger, for design details.

\subsubsection{Tapered Flight Design}

The flights of the auger slope downward in the radial direction at an angle of seven degrees. This tends to allow the recovered sample to sluff off the edges. By sloping the flights from the outside edge in towards the shaft, the material will be contained in a similar method as with the raised edge design. See Attachment 7, Tapered Flight Auger, for design details.

\subsection{Test Environment}

The tests will be conducted at the Engineering Testing Labs in the 305 Building. This area is an open bay, with space for performing the tests and for storing equipment. The samplers will be tested in two 
different types of waste simulants. The first is diatomaceous earth, which will simulate hard dry wastes. The second simulant is a mixture of urea and water, making a soft clay-like material. The testing will be indoors in a dry, non-hazardous atmosphere. No hazardous materials will be generated. Special environmental and safety considerations are not required beyond those of the normal building safety guidelines.

\subsection{Test Equipment}

The following test equipment is required:

- Auger deployment mechanism (modified auger assemb7y $\mathrm{H}-2-79960$ )

- New7y designed and fabricated auger bits

- Drums of simulants

- Sample extraction area and table

- Measuring devices, as required.

\subsection{Data}

Each sample will be weighed and the results tabulated on data sheets similar to that proposed in Attachment 8, Data Sheet. At least ten trials will be run for each bit design in each waste type. Additional samples may be taken until the modification is judged effective or not. The performance of the new bits will be compared with the performance achieved with the standard auger in each simulant. If multiple modifications result in increased recovery, those designs should be combined and tested for total effectiveness in a second phase of testing (not within scope of this test plan).

Recovery performance for the auger in these simulants has not been previously tested. However, the simulants are comparable to waste types where recoveries have been in the range of 20-80 percent. A middle range recovery is needed to better show variations in performance. If preliminary results indicate recovery below approximately 50 percent for all of the design modifications and the standard, a different simulant will be chosen.

\subsection{Criteria and Constraints}

The results of these tests are not required to meet a specific design criteria. The experiments are exploratory and developmental. The goal is to achieve any recovery improvements possible, by evaluating the various designs. Some may show no improvement at a11.

The basic design configuration of the auger sampler will be maintained. A17 modifications to the auger have been minor, and it is impossible to predict the exact quantity of improvement each will provide. Therefore, the testing engineer is given the flexibility to test the designs in any order and quantity judged as appropriate. 


\subsection{EXPECTED RESULTS}

The expectations for each design and rationalization for the modification are included with the descriptions for each item under 4.1, Test Items. As stated in 4.4, Data, the results of the modified augers will be compared to those of the standard auger, to determine their effectiveness. In general, this testing is expected to reveal that certain modifications can be made to the current auger configuration that will increase sample recovery.

\subsection{TEST PROCEDURE}

Testing will proceed in the sequence and quantity judged appropriate by the testing engineer. At least ten trials will be taken in each simulant for each design. The design changes may be tested individually or in groups. The simulant drums will be kept as consistent as possible, to avoid variations - over time.

The auger will be held vertically for a specific length of time after the sample has been pulled above the waste level. This will help to show if the sample will be lost out the bottom of the auger. The exact length of time will be determined at the time of testing and recorded on the data sheet (Attachment 8).

The following procedure shall be used as a guideline for beginning testing. The actual method used to obtain the samples will be documented in the test report.

1. Prepare auger assembiy.

2. Auger sample.

2a. If sheath design test, lower sheath.

3. Retract auger assembly.

4. Hold vertically for set time period.

5. Relocate assembly to extraction area.

6. Make notes of any observations.

7. Remove simulant from flutes of auger.

8. Weigh and record value.

9. Return sample media to drum and mix simulant.

10. Clean auger and sleeve with water then wipe dry.

Repeat for next sample.

\subsection{SAFETY}

Normal building and material safety guidelines will be adhered to. This testing presents no unusual safety risks and has been rated with the approval designator "N/A", per the document approval matrix in WHC-CM-3-5. Special safety considerations are not required for this test.

\subsection{QUALITY ASSURANCE}

Due to the exploratory nature of this testing, the activity has been rated "N/A" in the document approval matrix in WHC-CM-3-5. Quality Assurance reviews are not required. 


\section{WHC-SD-WM-TP-357 REV. 0}

\subsection{ORGANIZATION AND FUNCTIONAL RESPONSIBILITIES}

Characterization Equipment Improvement Engineers will have overall responsibility for this project with delegated responsibility where appropriate.

\subsection{SCHEDULE}

See Attachment 9, Schedule. 
WHC-SD-WM-TP-357 REV. 0

Attachment 1 Grooved Auger

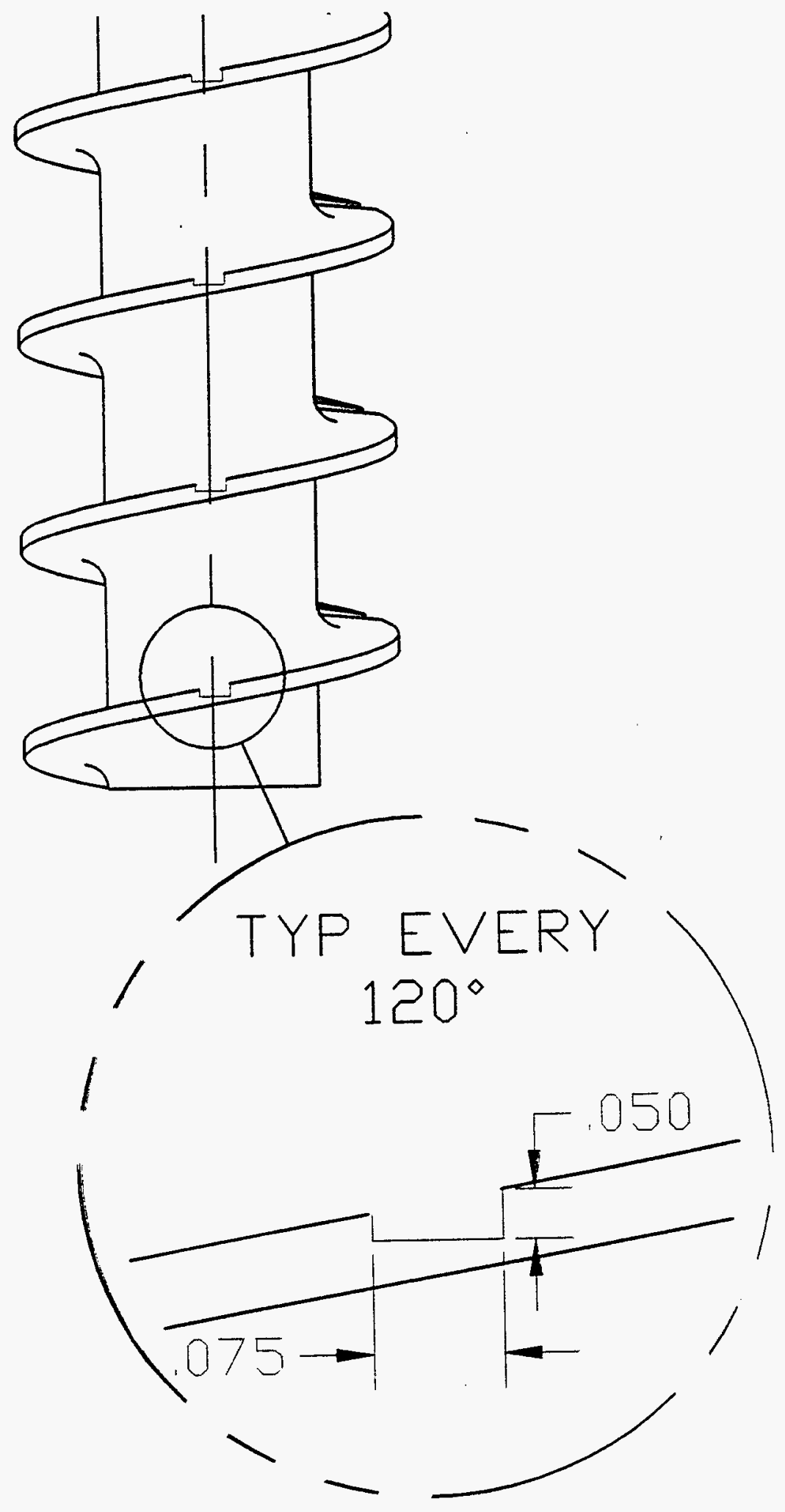




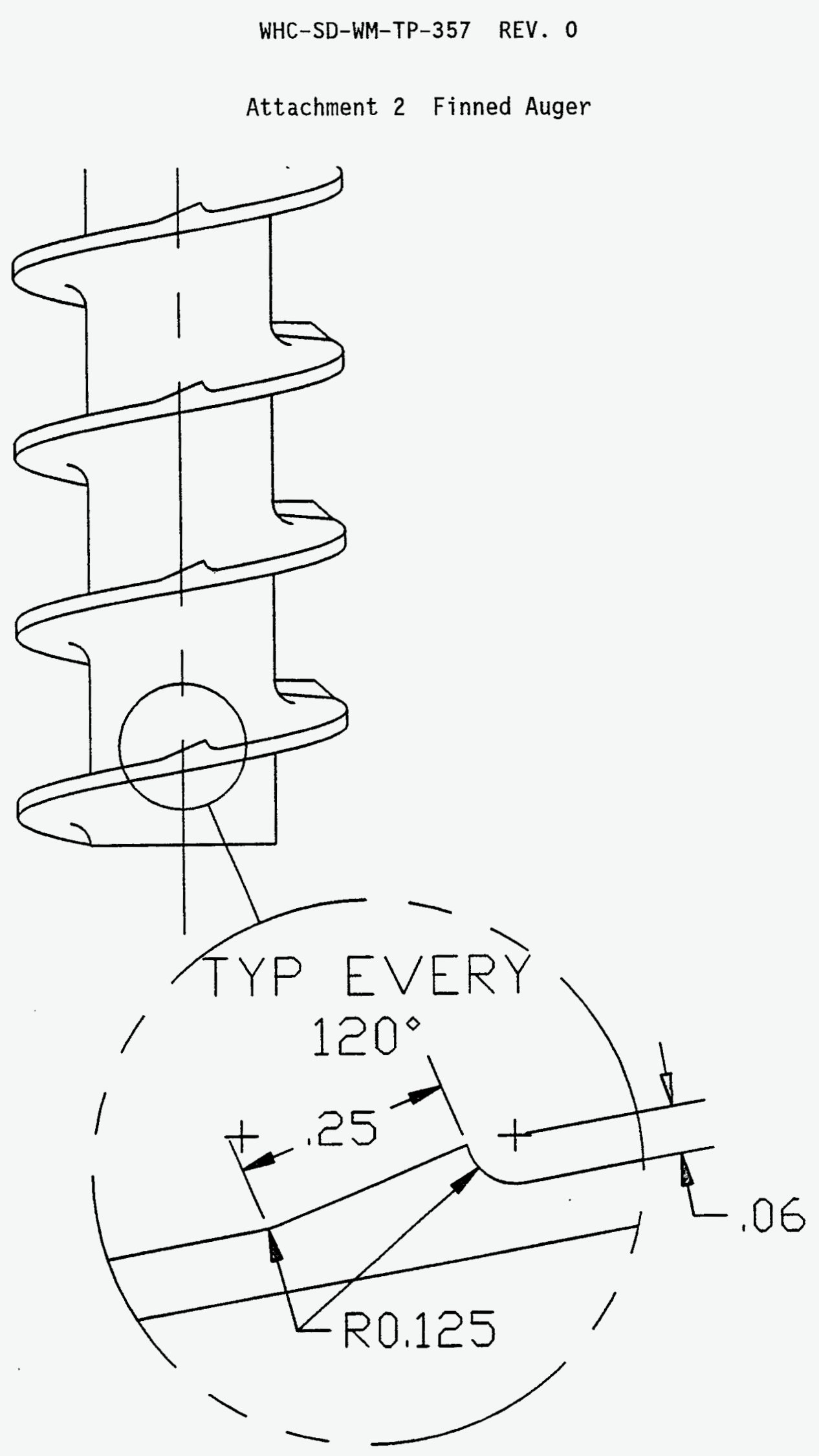

8 
WHC-SD-WM-TP-357 REV. 0

\section{Attachment 3 Small Shaft Auger}

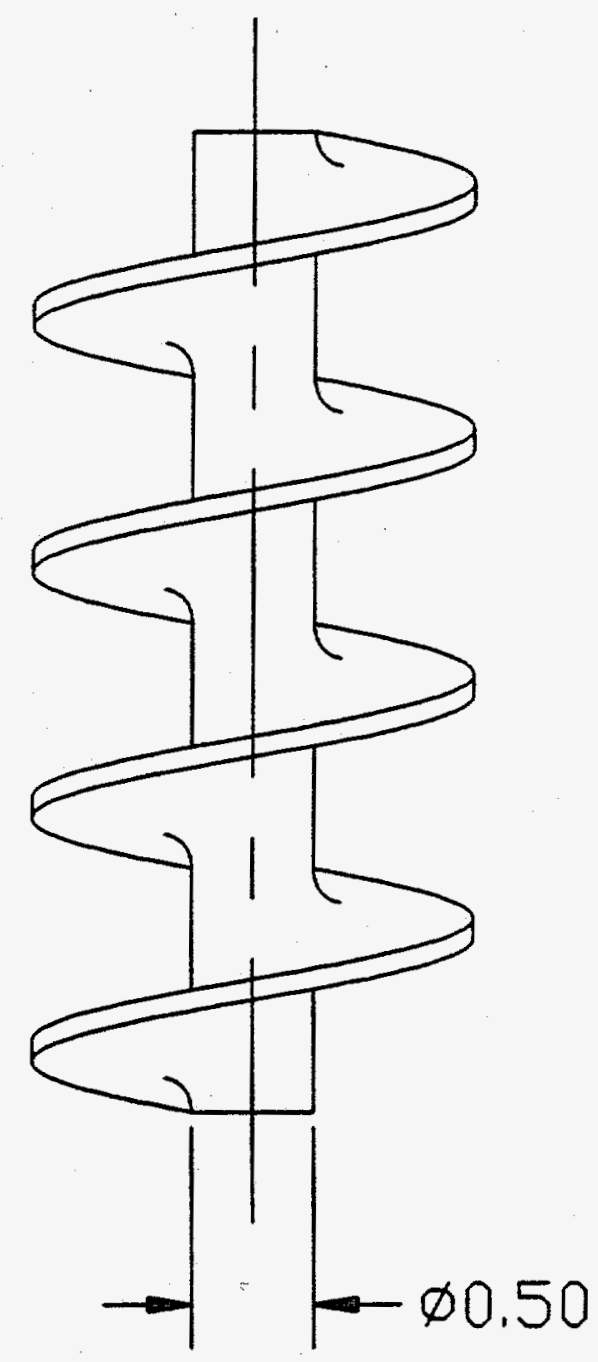


WHC-SD-WM-TP-357 REV. 0

Attachment 4 Sheathed Auger

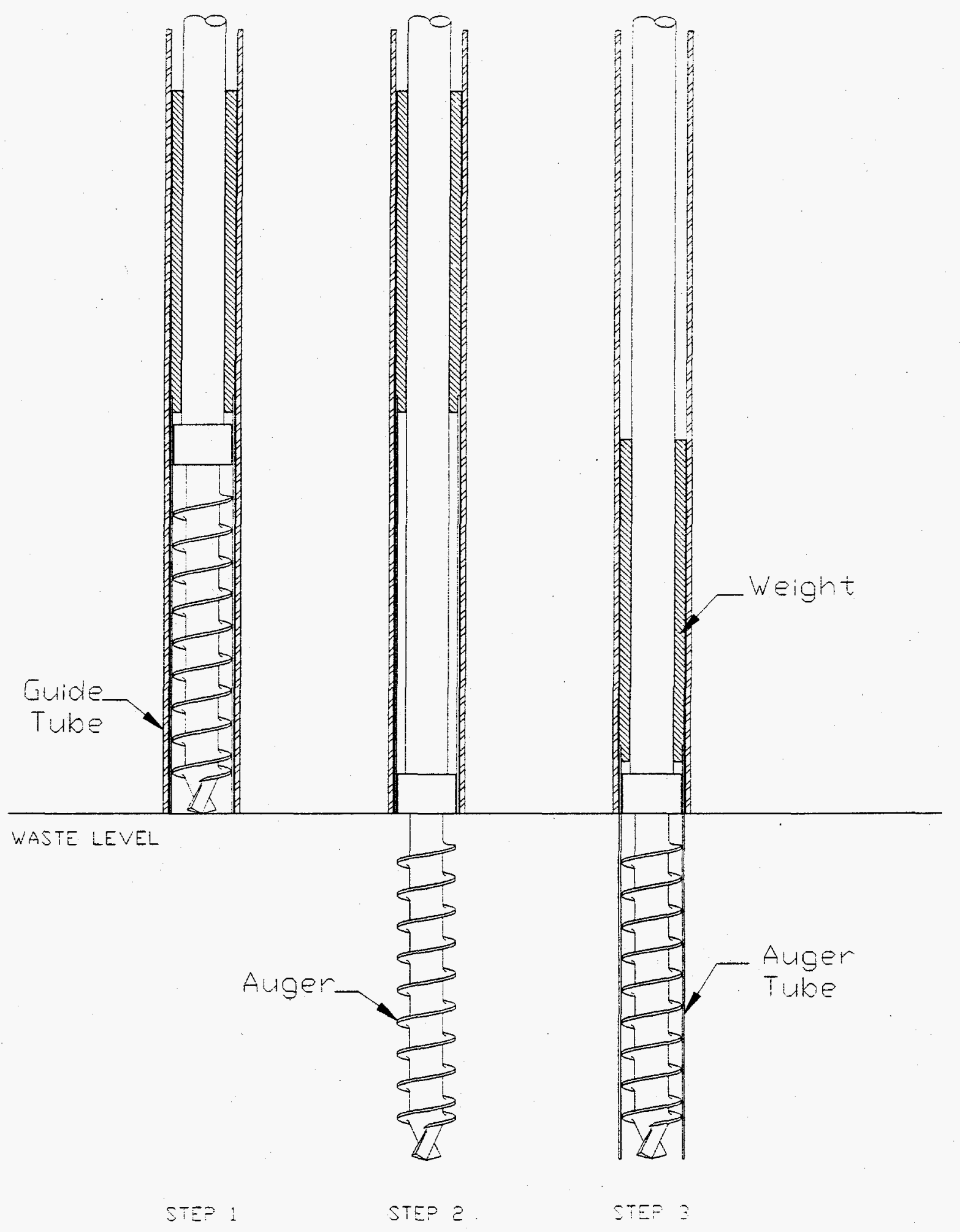


WHC-SD-WM-TP-357 REV. 0

Attachment 5 Raised Edge Auger
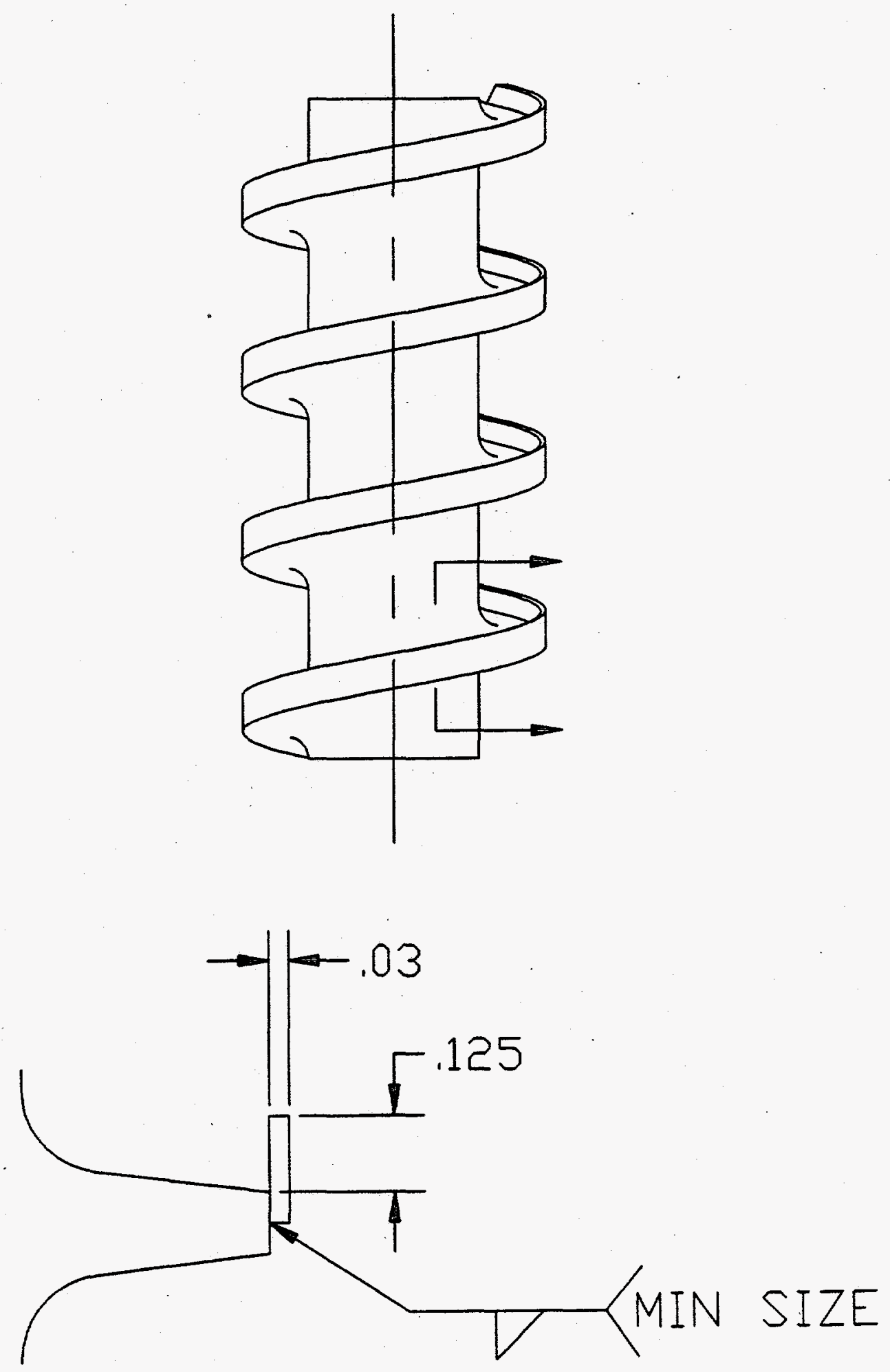
WHC-SD-WM-TP-357 REV. 0

Attachment 6 Shallow Pitch Auger

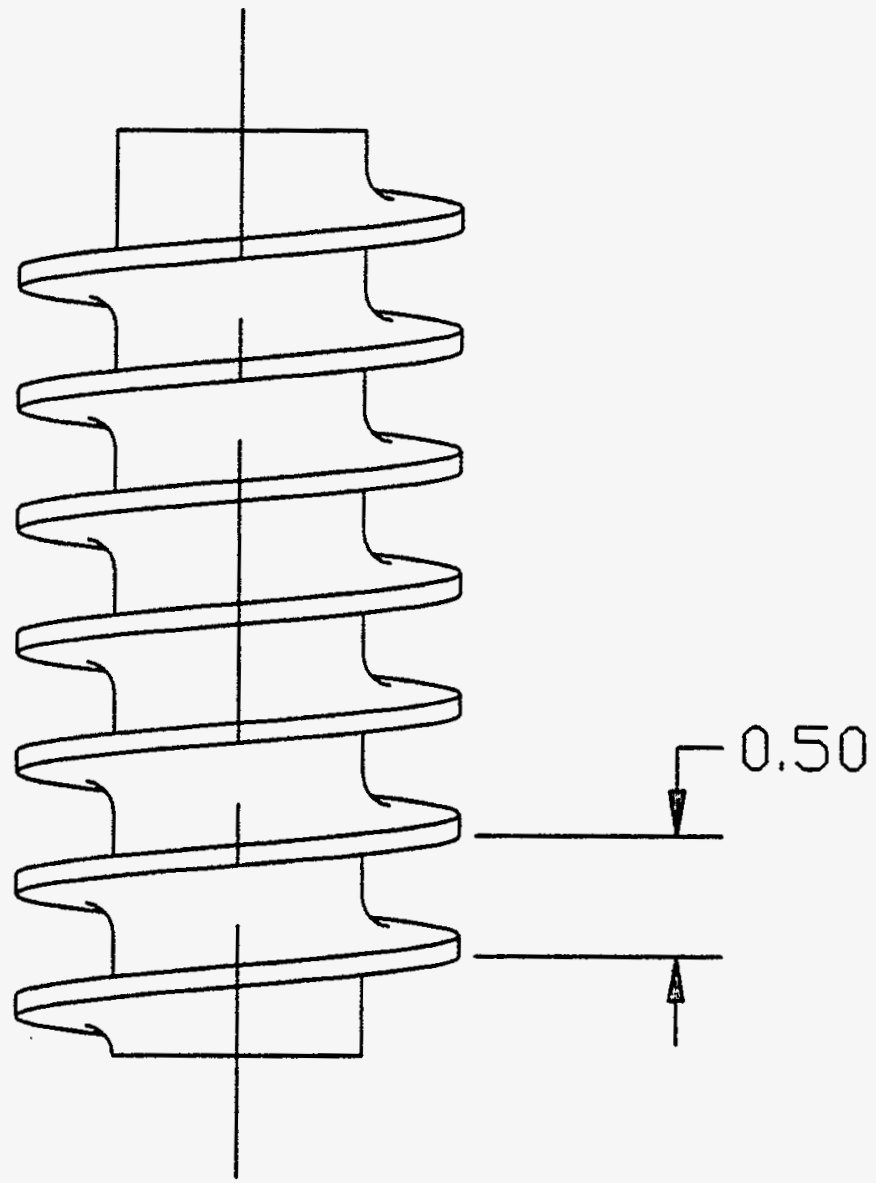


WHC-SD-WM-TP-357 REV. 0

Attachment 7 Tapered Flight Auger
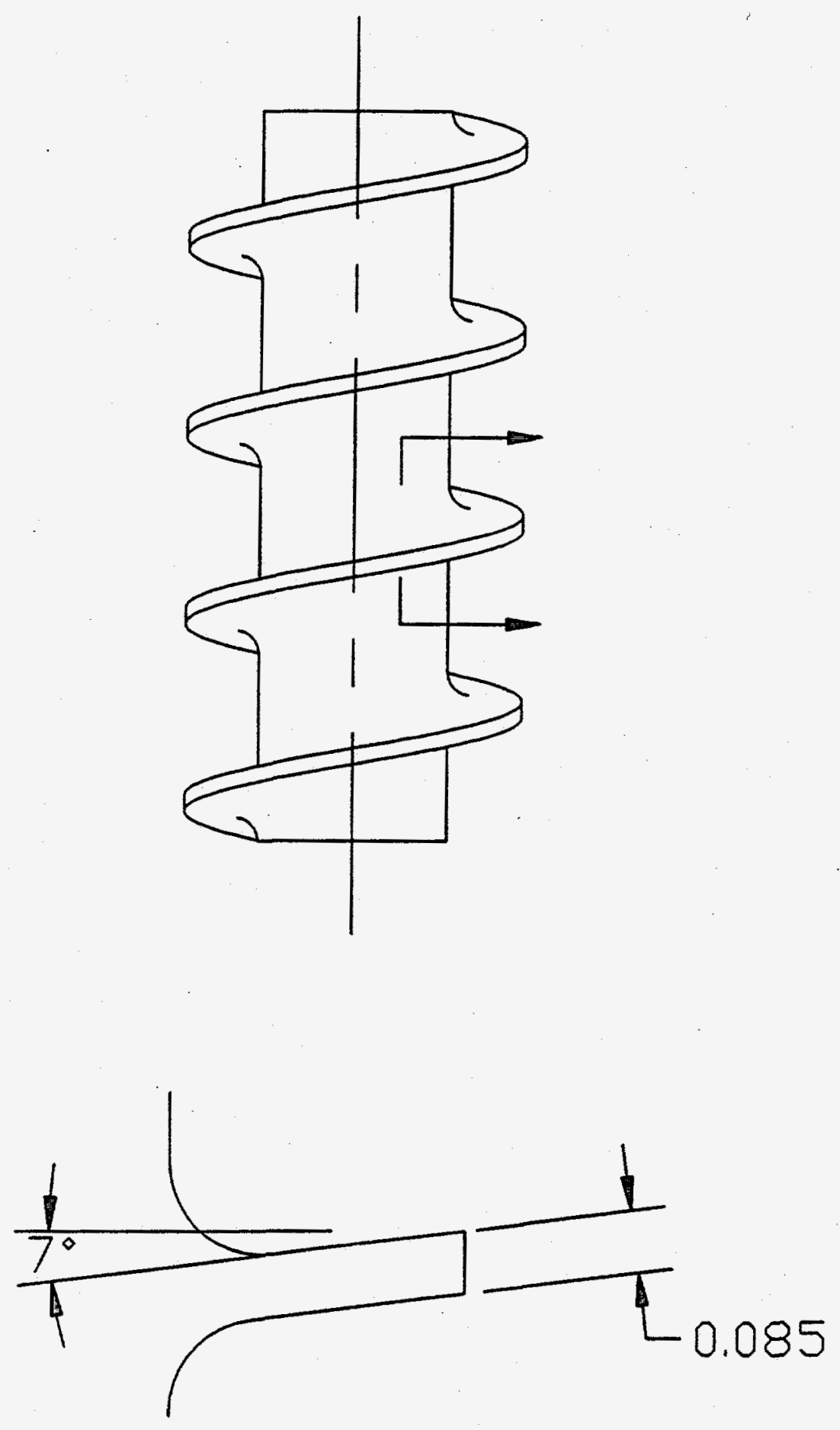

13 
WHC-SD-WM-TP-357 REV. 0

\section{ATTACHMENT 8 DATA SHEET}

AUGER TYPE:

SIMULANT: urea-mix diatom. earth

EXPECTED WEIGHT 100\% FULL (grams):

\begin{tabular}{||l|l|l|l|l||}
\hline \hline & Date & Time & $\begin{array}{l}\text { Weight } \\
\text { (grams) }\end{array}$ & \\
\hline 1 & & & & \\
\hline 2 & & & & \\
\hline 3 & & & & \\
\hline 4 & & & & \\
\hline 5 & & & & \\
\hline 6 & & & & \\
\hline 7 & & & & \\
\hline 8 & & & & \\
\hline 9 & & & & \\
\hline 10 & & & & \\
\hline 11 & & & & \\
\hline 12 & & & & \\
\hline 13 & & & & \\
\hline 14 & & & & \\
\hline 15 & & & & \\
\hline 16 & & & & \\
\hline 17 & & & & \\
\hline 18 & & & & \\
\hline 19 & & & & \\
\hline 20 & & & & \\
\hline 21 & & & & \\
\hline 22 & & & & \\
\hline 23 & & & & \\
\hline 24 & & & & \\
\hline \hline & & & & \\
\hline
\end{tabular}




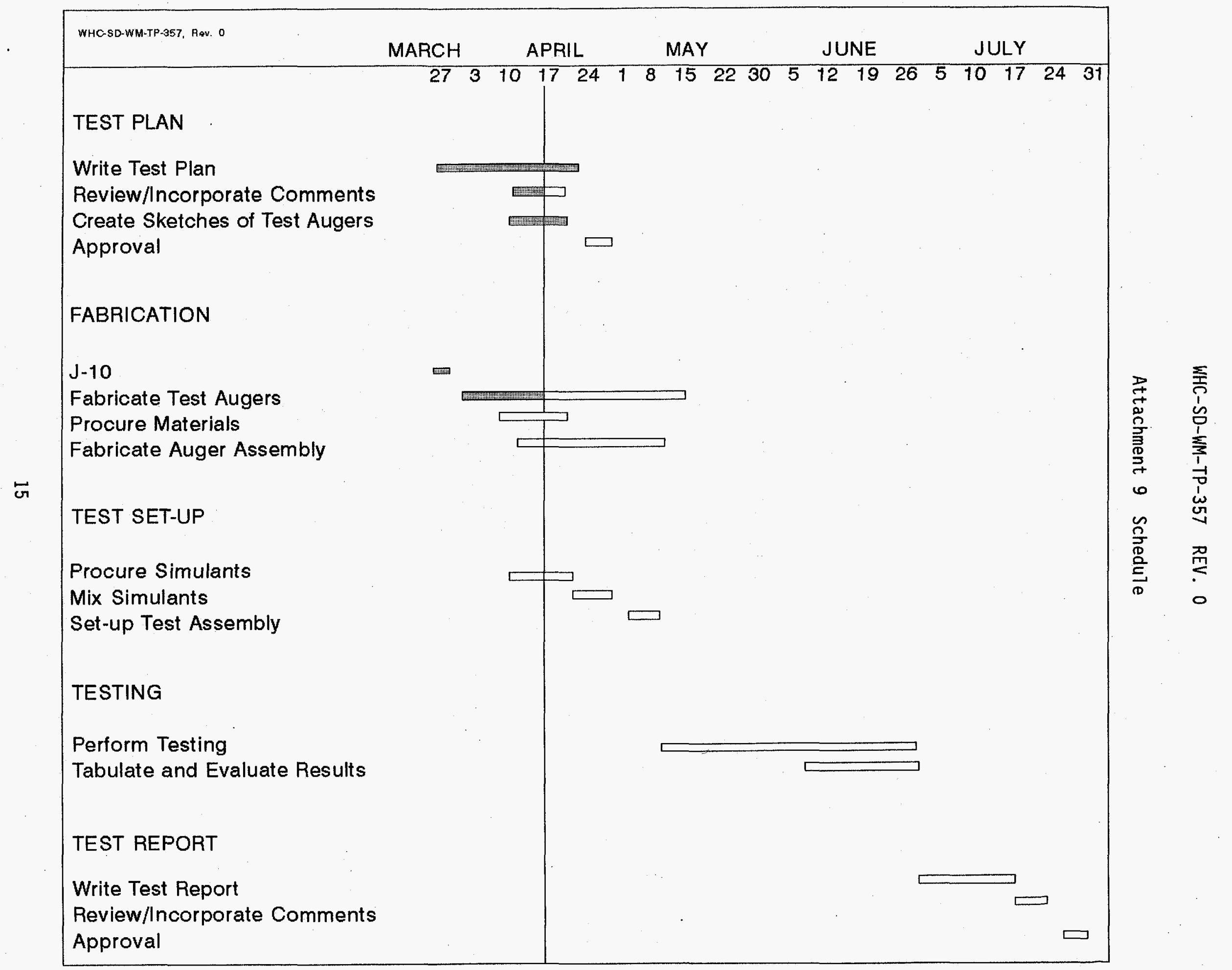

